\title{
Barium Ferrites Loaded $\mathrm{TiO}_{2}$ Usage In Photocatalytic Degradation of Rhodamine B Under Visible Light
}

\author{
Görünür Işık Altında Rodamin B'nin Fotokatalitik Parçalanmasında \\ Baryum Ferrit Yüklenmiş $\mathrm{TiO}_{2}$ Kullanılması
}

\author{
Research Article
}

\section{Özge Kerkez Kuyumcu}

Chemical Engineering Department, Faculty of Engineering, Marmara University, İstanbul, Turkey.

\section{A B S TR AC T}

\begin{abstract}
$\mathrm{n}$ the present study, the barium ferrites sample was synthesized by conventional citrate method as a first step, then it was used with different amounts in $\mathrm{TiO}_{2}$ synthesis via a soft hydrolysis method as a second step. $\mathrm{Re}$ sulted photocatalyst samples were named as $\mathrm{BaFts} / \mathrm{TiO}_{2}$. The samples were characterized by X-ray diffraction (XRD), UV-vis diffuse reflectance spectra (DRS) and scanning electron microscopy (SEM). The samples were tested in Rhodamine B degradation under visible light. Rhodamine B degradation efficiency was increased approximately 2.8 times with respect to the efficiency of the naked $\mathrm{TiO}_{2}$.
\end{abstract}

\section{Key Words}

Barium ferrite, titanium dioxide, photocatalysis, dye degradation.

\section{öz}

u çalışmada ilk basamakta baryum ferrit örneği klasik sitrat yöntemiyle sentezlenmiştir. İkinci basamakta bu örnek hidroliz yöntemi ile $\mathrm{TiO}_{2}$ sentezinde farklı miktarlarda kullanılmıştır. Elde edilen fotokatalizör örnekleri $\mathrm{BaFts} / \mathrm{TiO}_{2}$ olarak adlandırılmıştır. Örnekler X-ışını difraksiyonu (XRD), UV-görünür alan difüz reflektanSI (UV-vis DRS) ve taramalı elektron mikroskobu (SEM) ile karakterize edilmiştir. Örnekler, görünür ışık altında Rodamin B parçalanmasında kullanılmıştır. Rodamin B'nin parçalanma etkinliği, yalın $\mathrm{TiO}_{2}$ 'in etkinliğine kıyasla yaklaşık 2.8 kat artmıştır.

\section{Anahtar Kelimeler}

Baryum ferrit, titanyum dioksit, fotokataliz, boya parçalanması.

Article History: Received: Apr 22, 2017; Revised: Jun 25, 2017; Accepted: Oct 27, 2017; Available Online: Dec 25, 2017.

DOI: 10.15671/HJBC.2018.179

Correspondence to: Ö.K. Kuyumcu, Chemical Engineering Dep., Faculty of Engineering, Marmara University, İstanbul, Turkey. 


\section{INTRODUCTION}

Th e presence of organic dyes in wastewaters is undesirable in terms of both aesthetics and human health. Organic dyes discharged to the nature with wastewaters, are hazardous for the ecosystem because of their non-biodegradability and toxicity. Numerous methods have been reported for the wastewater treatment. These physical, chemical and biological methods have disadvantages [1,2]. Heterogeneous photocatalysis, which occurs as an important part of the advanced oxidation process, is an efficient method for the wastewater treatment. Redox reactions start with the photogenerated electron-hole pair on the semiconductor photocatalyst surface by absorbing the energy required. $\mathrm{TiO}_{2}$ is the most suitable photocatalyst because of its inertness, stability and high oxidative ability $[3,4]$. But $\mathrm{TiO}_{2}$ has a disadvantage of nonfunctionality beyond the 400 $\mathrm{nm}$ wavelength; it can be activated only by UV irradiation because of its wide band gap. So the studies have been focused on sensitizing $\mathrm{TiO}_{2}$ to the visible light by several types of dopants for usage with sunlight [5].

Generally noble metals ( $\mathrm{Ag}, \mathrm{Au}, \mathrm{Pt}$ ) or transition metals $(\mathrm{V}, \mathrm{Cr}, \mathrm{Mn}, \mathrm{Co})$ doped $\mathrm{TiO}_{2}$ have been synthesized for different photocatalytic reactions [6-8]. Another way is synthesizing $\mathrm{TiO}_{2}$ as a coupled semiconductor with a narrow band gap material such as $\mathrm{CdS}, \mathrm{WO}_{3}[9,10]$. Recently, ferrites have had great attraction for the various photocatalytic processes because of their relatively narrow band gap [11]. Also, the precursor is abundant so the cost of the photocatalyst can be lowered by usage of the ferrites. If they occupy a sufficient amount in the photocatalyst, the magnetic properties facilitate the separation from the reaction media.

$\mathrm{ZnFe}_{2} \mathrm{O}_{4^{\prime}} \mathrm{CuFe}_{2} \mathrm{O}_{4^{\prime}} \mathrm{NiFe}_{2} \mathrm{O}_{4^{\prime}} \mathrm{MnFe}_{2} \mathrm{O}_{4}$ and $\mathrm{CoFe}_{2} \mathrm{O}_{4}$ have been widely used in photocatalytic processes [12-20]. Not only ferrites have been used singly, but also ferrites have been used as composites. For example, very recently $\mathrm{ZnFe}_{2} \mathrm{O}_{4}$ multi-porous microbricks/graphene hybrid photocatalyst was used for photocatalytic degradation of p-chlorophenol under visible light irradiation $(\lambda$ $>420 \mathrm{~nm}$ ) [21]. In a similar study, photocatalytic degradation of methylene blue was performed with $\mathrm{ZnFe}_{2} \mathrm{O}_{4} / \mathrm{ZnO}$ nanocomposites immobilized on graphene [22]. Furthermore $\mathrm{Ca}^{2+}, \mathrm{Mg}^{2+}$ and $\mathrm{Ba}^{2+}$ cations have been used in $\mathrm{MFe}_{2} \mathrm{O}_{4}$ structure $[11,23]$. Photocatalytic degradation of rhodamine $\mathrm{B}$ was studied with $\mathrm{MgFe}_{2} \mathrm{O}_{4} / \mathrm{TiO}_{2}$ composite prepared by milling and calcining [24]. The present metal cation in the lattice affects the stability and redox properties of the ferrites. So the different ferrites can show different photocatalytic activities according to the consisting metal, synthesis route and the other characteristic properties.

Barium ferrite is the least used ferrite compound in photocatalytic processes; there are limited studies with it. $\mathrm{BaFe}_{2} \mathrm{O}_{4}$ was used in photocatalytic degradation of methyl orange under UV light [25], $\mathrm{BaFe}_{2} \mathrm{O}_{4}$ core/silica/ $\mathrm{TiO}_{2}$ shell was used in the photodegradation of Procion red MX-5B dye under UV illumination [26]. Very recently, $\mathrm{BaFe}_{12} \mathrm{O}_{19}$ (band gap $1.77 \mathrm{eV}$ ) was used in the photocatalytic methylene blue degradation under visible light irradiation with $\mathrm{H}_{2} \mathrm{O}_{2}$ [27]. Barium ferrite is a highly stable, inert material that is advantageous for photodegradation reactions [28].

Rhodamine $B(R B)$ is a toxic dye that is used in textile industry. It should be eliminated from the wastewater because of the hazardous effects on the human beings and animals.

All this knowledge was led to investigate the activity of barium ferrites $/ \mathrm{TiO}_{2}$ under visible light for photocatalytic degradation of RB. In this study barium ferrites were synthesized by citrate method, then $\mathrm{TiO}_{2}$ was prepared in the presence of various amounts of barium ferrites. The photocatalysts were tested in terms of barium ferrites ratio in the total photocatalysts, initial RB concentration, catalyst amount and $\mathrm{pH}$.

\section{MATERIALS and METHODS}

\section{Materials}

All reagents used in the experiments were used without further purification. $\mathrm{BaCl}_{2} \cdot 2 \mathrm{H}_{2} \mathrm{O}$ (Merck), $\mathrm{Fe}\left(\mathrm{NO}_{3}\right)_{3} \cdot 9 \mathrm{H}_{2} \mathrm{O}$ (Merck), citric acid $\mathrm{C}_{6} \mathrm{H}_{8} \mathrm{O}_{7}$ (Merck), $25 \% \mathrm{NH}_{3}$ solution (Merck), titanium isopropoxide 97\% Ti[OCH $\left.\left(\mathrm{CH}_{3}\right)_{2}\right]_{4}$ (Aldrich), Triethanolamine (TEA) $\mathrm{C}_{6} \mathrm{H}_{15} \mathrm{NO}_{3}$ (Merck), 1-propanol $\mathrm{C}_{3} \mathrm{H}_{7} \mathrm{OH}$ (Merck), acetic acid $\mathrm{CH}_{3} \mathrm{COOH}$ (Merck) were used in the synthesis of the photocatalysts. 


\section{Synthesis of Photocatalysts}

Barium ferrite was prepared according to citrate method published previously [11]. The aqueous solution of $\mathrm{Fe}\left(\mathrm{NO}_{3}\right)_{3} \cdot 9 \mathrm{H}_{2} \mathrm{O}$ and $\mathrm{BaCl} \cdot 2 \mathrm{H}_{2} \mathrm{O}$ was prepared in molar ratio of $\mathrm{Fe}^{3+}: \mathrm{Ba}^{2+}=2: 1$. The concentration of $\mathrm{Ba}^{2+}$ ion in the solution was 0.25 $M$. The mixture was magnetically stirred for 30 min. $3 \mathrm{~g}$ of $\mathrm{C}_{6} \mathrm{H}_{8} \mathrm{O}_{7}$ was added and the mixture was stirred at $60^{\circ} \mathrm{C}$, approximately $6 \mathrm{ml}$ of ammonia solution was added by dropwise until its $\mathrm{pH}$ value became 6-7. After stirring $8 \mathrm{~h}$, the gel was dried at $120^{\circ} \mathrm{C}$ and calcined at $900^{\circ} \mathrm{C}$ for $1 \mathrm{~h}$.

$\mathrm{BaFts} / \mathrm{TiO}_{2}$ samples were prepared by a soft hydrolysis method. Dispersion of BaFts was prepared under ultrasound in glacial acetic acid as $0.066 \mathrm{~g} / \mathrm{mL}$. Separately, a mixture of $\mathrm{Ti}\left[\mathrm{OCH}\left(\mathrm{CH}_{3}\right)_{2}\right]_{4}$ and TEA was prepared in 1-propanol. A specified amount of BaFts dispersion was added to this mixture to obtain various $\mathrm{w} / \mathrm{w}$ ratios of BaFts/photocatalyst (0.5\%, 1.0\%, 2.5\%, 5.0\%). The mixture was kept under ultrasound for $30 \mathrm{~min}$ and $\mathrm{H}_{2} \mathrm{O}$ was added to achieve the hydrolysis reaction for the synthesis of $\mathrm{TiO}_{2}$. And then $10 \mathrm{~mL}$ 1-propanol was added to dilute. The final volume of the mixture was $30 \mathrm{~mL}$. The molar ratio of Ti:TEA: $\mathrm{H}_{2} \mathrm{O}$ was 1:1:2. The final concentration of $\mathrm{Ti}^{4+}$ in the mixture was $0.5 \mathrm{M}$. The mixture was kept at $70^{\circ} \mathrm{C}$ for overnight and at $100^{\circ} \mathrm{C}$ for $2 \mathrm{~h}$. Finally the as-prepared gel was calcined at $500^{\circ} \mathrm{C}$ for $1 \mathrm{~h}$. BaFts $/ \mathrm{TiO}_{2}$ samples did not show the magnetic separation because of the low loading amount of ferrites.

\section{Characterization}

The photocatalyst samples were characterized by powder X-ray diffractions (XRD) using Rigaku D/ Max-2200 diffractometer with CuK $\alpha(\lambda=1.5405)$ radiation. Samples were scanned from $20^{\circ}$ to $85^{\circ}$ at a rate of $2 \% \mathrm{~min}$ (in $2 \theta$ ). The diffuse reflectance spectra (DRS) of the samples in the wavelength range $200-800 \mathrm{~nm}$ were obtained by Ocean Optics UV-vis scanning spectrophotometer using $\mathrm{BaSO}_{4}$ as reference. The morphological characteristics of the samples and backscattered electron analysis were carried out by Field Emission Scanning Electron Microscopy (FE-SEM, FEI Quanta FEG 450).

\section{Photocatalytic Reactions}

Photocatalytic reactions were performed with a
$100 \mathrm{ml}$ total volume of aqueous Rhodamine B solution with specific initial concentrations. The solution was taken to a $10 \mathrm{~cm}$ diameter reaction vessel placed in a reaction chamber. At the top of the reaction chamber the light source (Horoz, HL 88105105 W DAYLIGHT, main emission wavelength is $530 \mathrm{~nm}$ ) was mounted, the distance between the surface of RB solution and the lamp was 20 $\mathrm{cm}$. A particular amount of photocatalyst $(0.5$ $2.0 \mathrm{~g} / \mathrm{L}$ ) added and then the mixture was kept in the dark under stirring for 2 hours to reach the adsorption equilibrium. Before the light switching, a zero time sample was taken to determine the dye concentration after the adsorption. The temperature of the reaction mixture was kept constant at $25 \pm 2^{\circ} \mathrm{C}$. Reaction aliquots were taken periodically from reaction media and filtered. RB concentration was followed by PG Instruments UV-Vis spectrophotometer at $555 \mathrm{~nm}$. Degradation efficiencies were calculated by Equation 1 where $C_{d y e_{1}}=$ dye concentration at time t. $C_{d y e_{0}}=$ dye concentration at time 0 .

Degradation efficiency (\%) $=\frac{\left(C_{d y e_{0}}-C_{d y e_{t}}\right)}{C_{d y e_{0}}} x 100$

\section{RESULTS and DISCUSSION}

\section{Characterization Results}

Figure 1a represents the XRD pattern of prepared barium ferrites by the citrate method. The as prepared sample showed three phases from ferrite family. The dominant phase is $\mathrm{BaFe}_{12} \mathrm{O}_{19}$ which is identified by card no 00-007-0276. The diffraction peaks at $30.3^{\circ}, 32.1^{\circ}, 34.1^{\circ}, 37.1^{\circ}, 40.4^{\circ}$, $55^{\circ}$ and $56.6^{\circ}$ correspond to the planes of 110,107 , 200, 203, 205, 217 and 2011 of barium hexaferrite phase structure, respectively. $\mathrm{BaFe}_{2} \mathrm{O}_{4}$ phase is identified by the most severe two peaks of pattern with card no 01-073-3906. The diffraction peaks at $28.7^{\circ}$ and $32.7^{\circ}$ correspond to the planes of 221 and 061 of barium monoferrite phase structure. Finally, $\alpha-\mathrm{Fe}_{2} \mathrm{O}_{3}$ is characterized by the peaks at $35.2^{\circ}$ and $40.8^{\circ}$ which correspond to the planes of 110 and 113 of hematite structure with card no 00-033-0664 [29].

Figure $1 \mathrm{~b}$ shows the XRD pattern of $\mathrm{BaFts} / \mathrm{TiO}_{2}$ photocatalysts prepared with different amounts of the dopant. The characteristic peaks of $\mathrm{BaFe}_{12} \mathrm{O}_{19}$ or 

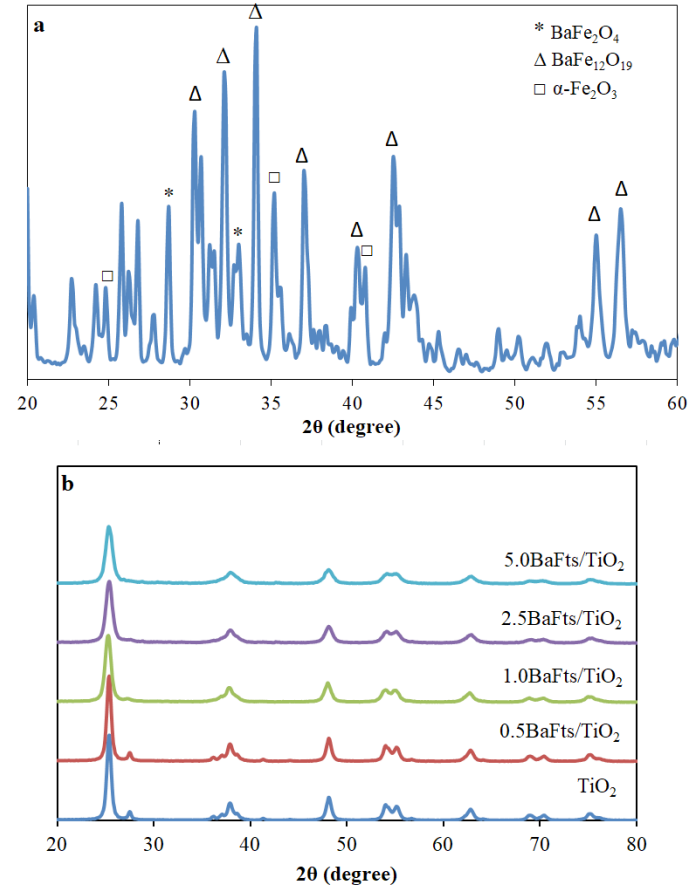

Figure 1. XRD pattern of barium ferrites synthesized by citrate method (a); XRD pattern of the $\mathrm{BaFts} / \mathrm{TiO}_{2}$ photocatalysts (b).

any other ferrite phase did not observe at the XRD pattern of none of the doped photocatalysts. It is attributed to low concentration of ferrites phase in the structure. However, there is an effect that can not be ignored, the intensity of the peaks which belongs to $\mathrm{TiO}_{2}$ anatase phase decreased as the dopant amount increases. The diffraction patterns of all $\mathrm{BaFts} / \mathrm{TiO}_{2}$ photocatalyst samples showed the characteristic peaks of anatase phase of $\mathrm{TiO}_{2}$ determined by JCPDS card no. 21-1272. As shown in Figure $1 \mathrm{~b}$, the diffraction peaks at $25.5^{\circ}, 37.9^{\circ}$,

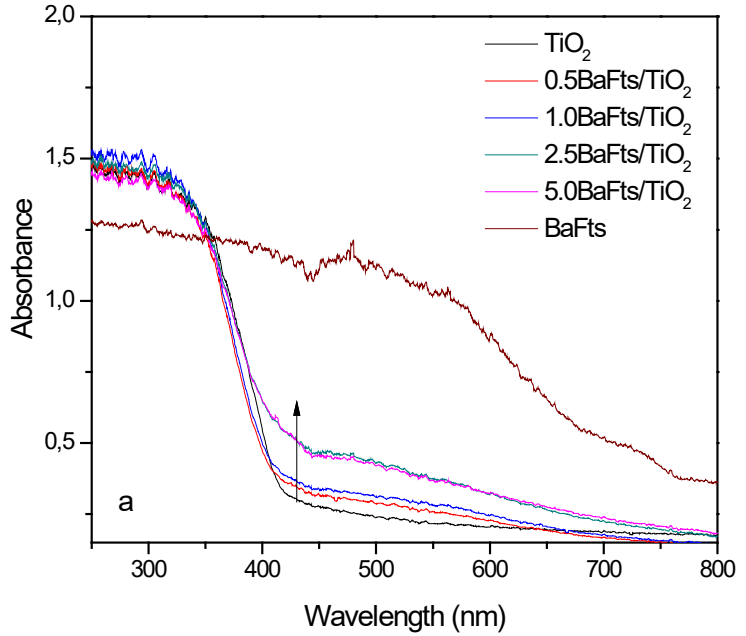

Figure 2. UV-vis absorption spectra of the photocatalysts (a); Band gap energy calculation curves of the photocatalysts (b)

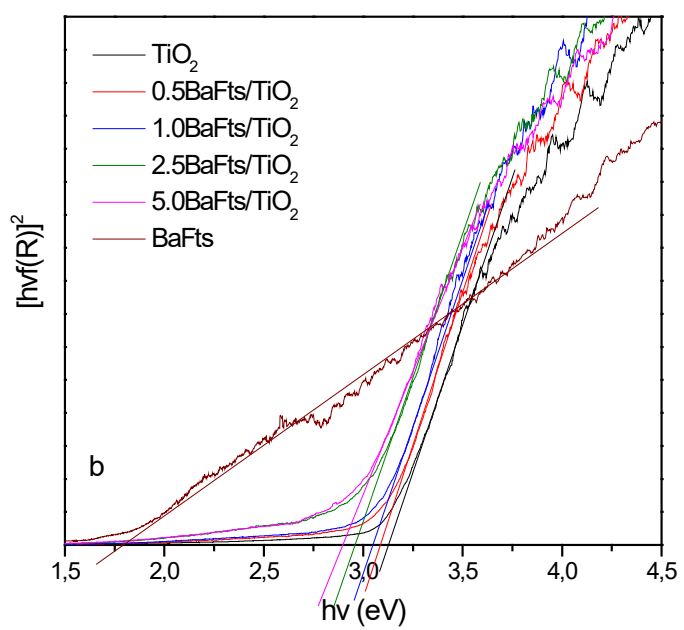

$48.3^{\circ}$, and $62.9^{\circ}$ correspond to the crystal planes of $101,004,200$, and 204 of $\mathrm{TiO}_{2}$ anatase phase structure.

The crystallite sizes were calculated by Scherrer equation given in Equation 2 where $\mathrm{k}$ is a constant between 0.8 and $1.39, \lambda$ is the wavelength of the $X$-rays, $\beta$ is the full width at half maximum, $\theta$ is the Bragg angle, and $D$ is the crystallite size $(\AA)$.

$$
D_{h k l}=\frac{k \cdot \lambda}{\beta \cdot \cos \theta}
$$

The mean crystallite sizes, given in Table 1, were calculated as using the maximum intensity peak with $\mathrm{I} / \mathrm{I}_{0}=100$. The mean crystallite sizes of the BaFts/ $\mathrm{TiO}_{2}$ photocatalysts are lower than naked $\mathrm{TiO}_{2}$ and barium ferrite structure. It was realized that the presence of $\mathrm{BaFts}$ during $\mathrm{TiO}_{2}$ formation resulted lower crystallite size of doped photocatalysts. Even, when the amount of BaFts was increased from 0.5 to 1.0 the mean crystallite size was decreased from $14.3 \mathrm{~nm}$ to $12.8 \mathrm{~nm}$. For the higher amounts of BaFts, no more reduction was observed in crystallite size; which indicated there is a limiting level in terms of BaFts amount for crystallite size reduction of doped

Figure 2a represents the UV-vis absorption spectra of the photocatalysts. As expected, the naked $\mathrm{TiO}_{2}$ showed the minimum visible light absorbance. The naked BaFts showed quite excess absorbance in visible light. Coupling of $\mathrm{TiO}_{2}$ with BaFts enhanced the absorption in the visible light photocatalysts. 


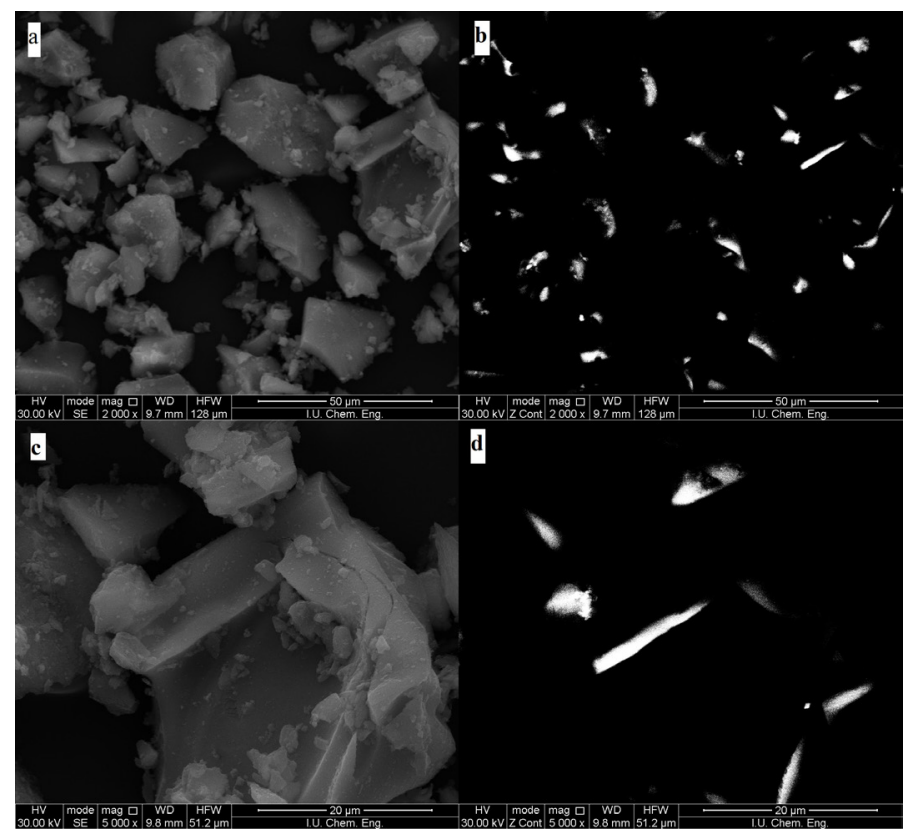

Figure 3. SEM images of the photocatalysts $(a, c)$, SEM images of back scattered electron analysis of the photocatalysts $(b, d)$.

range (>400 $\mathrm{nm})$. The visible light absorbance of the photocatalysts increased as the molar ratio of BaFts increases. The direct band gap energy of the samples was calculated by using the formula in Equation 3 where $E_{g}$ is the band gap energy, $h$ is Planck's constant, $v$ is the frequency of vibration, $\mathrm{hv}$ is the photon energy, $\mathrm{A}$ is a proportional constant and $\alpha$ is the absorption coefficient.

$$
(\mathrm{hv} \pm)^{1 / n}=\mathrm{A}\left(\mathrm{hv}-\mathrm{E}_{\mathrm{g}}\right)
$$

The absorbance or Kubelka-Munk function of the reflectance $(f(R))$ is proportional to the absorption coefficient, a. $[30,31] . n=1 / 2$ is used assuming the direct allowed transitions. A plot of $(h v f(R))^{2}$ versus photon energy, hv (Figure $2 b$ ) was given for all the photocatalysts explained by the Tauc method [32-34]. The calculated band gap energies of the prepared photocatalyst samples were given in Table 1. In agreement with the high absorbance in visible range BaFts has $1.80 \mathrm{eV}$ band gap energy, and with the addition of it to $\mathrm{TiO}_{2}$ the band gap energy decreases.

Figure 3 represents the SEM images of $1.0 \mathrm{BaFts} /$ $\mathrm{TiO}_{2}$ in different magnifications. Figure $3 \mathrm{~b}$ and $3 \mathrm{~d}$ shows the back scattered electron analysis images of Figure 3a and 3c, respectively. Back scattered electron analysis was performed to detect the BaFts phases on the sample's surface topography. The heavy molecule barium ferrites appeared brighter in the images. Thus, it is confirmed that the photocatalyst samples contain homogeneously distributed barium ferrites in the structure.

Table 1. Characterization results of prepared photocatalysts.

\begin{tabular}{ccccc}
\hline Photocatalyst & Phase & Diffraction Angle $\left(^{\circ}\right)$ & Crystallite size (nm) & Band gap (eV) \\
\hline $\mathrm{TiO}_{2}$ & Anatase & 25.4 & 19.2 & 3.09 \\
\hline $0.5 \mathrm{BaFts} / \mathrm{TiO}_{2}$ & Anatase & 25.3 & 14.3 & 3.05 \\
\hline $1.0 \mathrm{BaFts} / \mathrm{TiO}_{2}$ & Anatase & 25.3 & 12.8 & 3.03 \\
\hline $2.5 \mathrm{BaFts} / \mathrm{TiO}_{2}$ & Anatase & 25.4 & 12.8 & 2.98 \\
\hline $5.0 \mathrm{BaFts} / \mathrm{TiO}_{2}$ & Anatase & 25.4 & 12.8 & 2.95 \\
\hline Barium ferrites & $\mathrm{BaFe}_{12} \mathrm{O}_{19}, \mathrm{BaFe}_{2} \mathrm{O}_{4}$ & 34.1 & 39.2 & 1.80 \\
\hline
\end{tabular}


Photocatalytic Activity of BaFts/ $/ \mathrm{TiO}_{2}$ samples Figure 4 shows the degradation results corresponding to every thirtieth minute during the reaction time. The naked $\mathrm{TiO}_{2}$ showed the lowest activity. This is attributed to a wide band gap of $\mathrm{TiO}_{2}$, thus limited activation occurs by visible light. When barium ferrites were added to $\mathrm{TiO}_{2}$, the activity for degradation of Rhodamine $\mathrm{B}$ was increased. The optimum barium ferrite ratio was identified for maximum degradation; at the end of the $4 \mathrm{~h}$ reaction time, $69 \%$ degradation was achieved by $1.0 \mathrm{BaFts} / \mathrm{TiO}_{2}$ as seen in Figure 4 and Table 1. Band gap of $1.0 \mathrm{BaFts} / \mathrm{TiO}_{2}$ was calculated as $3.03 \mathrm{eV}, 0.5 \mathrm{BaFts} / \mathrm{TiO}_{2}$ was 3.05 $\mathrm{eV}$ and the naked $\mathrm{TiO}_{2}$ was $3.09 \mathrm{eV}$. Namely, as barium ferrite's amount increases in the photocatalyst structure, band gap decreases and activity under visible light increases. But, this situation continues to reach the optimum amount of the barium ferrites. It is reported, when barium ferrite amount was increased from 1.0 to 2.5, the degradation decreased from $69 \%$ to $59 \%$. Even $5.0 \mathrm{BaFts} / \mathrm{TiO}_{2}$ showed $44 \%$ conversion despite its lowest band gap $(2.95 \mathrm{eV})$. The optimum addition amount of barium ferrites was found as $1.0 \%(\mathrm{w} / \mathrm{w})$ barium ferrites/photocatalyst.

As a result of the previous experimental set, 1.0 BaFts $/ \mathrm{TiO}_{2}$ achieved the highest activity. So this sample was used in all other experiments to obtain optimum reaction conditions. Figure 5 shows the degradation efficiency, according to the different photocatalyst loadings. An increase was observed in the degradation efficiency when the photocatalyst dosage was increased from $0.5 \mathrm{~g} / \mathrm{L}$ to $1.5 \mathrm{~g} / \mathrm{L}$. The degradation efficiencies were $51 \%$ and $84 \%$ for $0.5 \mathrm{~g} / \mathrm{L}$ to $1.5 \mathrm{~g} / \mathrm{L}$, respectively. When

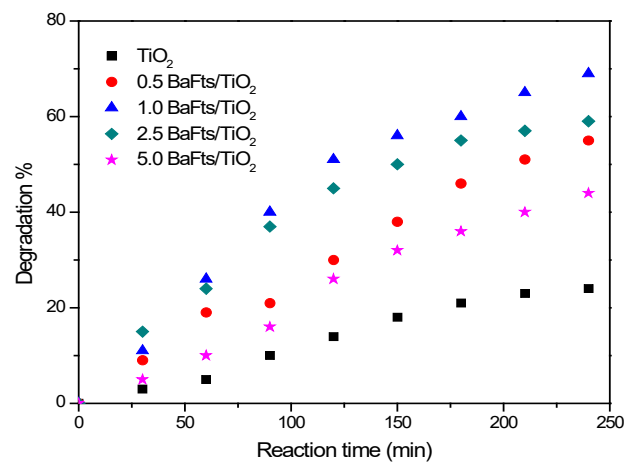

Figure 4. Rhodamine $B$ degradation results under visible light (main wavelength $530 \mathrm{~nm}$ ). the photocatalyst dosage was increased to $2.0 \mathrm{~g} / \mathrm{L}$, the degradation efficiency decreased to $55 \%$. This situation was attributed to surface area loss due to agglomeration. High photocatalyst loading caused agglomeration and the photocatalyst surface became unavailable for photon absorption [4].

Different initial concentrations (5-20 ppm) were studied. Figure 6 shows the degradation $\%$ values versus irradiation time with different initial rhodamine B concentrations. An inverse relation was observed between the initial dye concentration and the degradation efficiency. As the initial dye concentration increased, the degradation efficiency decreased. This result is attributed to the lower adsorption of dye at higher initial concentrations. Thus, the remaining dissolved dye (unadsorbed) hindered the photocatalyst to absorp the photon $[1,35]$. The maximum degradation was achieved with $5 \mathrm{ppm}$ initial dye degradation using $1 \mathrm{~g} / \mathrm{L} 1.0 \mathrm{BaFts} / \mathrm{TiO}_{2}$; the value is $93.5 \%$.

It is important to examine the $\mathrm{pH}$ effect on photocatalytic reactions because $\mathrm{pH}$ is a determining factor to complete removal of the dye. That is related to ionization state of both the catalyst surface and reactant [36]. Figure 7 shows the degradation $\%$ values versus the initial $\mathrm{pH}$ of the rhodamine B solutions. $\mathrm{pH}(2.5,4.5,6.5$, 9.5) effect on the photocatalytic degradation of rhodamine B (10 ppm) was studied under visible light with $1 \mathrm{~g} / \mathrm{L} 1.0 \mathrm{BaFts} / \mathrm{TiO}_{2}$ photocatalyst. The maximum degradation efficiency was achieved at $\mathrm{pH} 2.5$ (83.5\%). Among the range of $\mathrm{pH}$ 2.5-9.5 the degradation efficiency decreased with the $\mathrm{pH}$. $\mathrm{TiO}_{2}$ surface charges are related to $\mathrm{pH}$ as follows; if

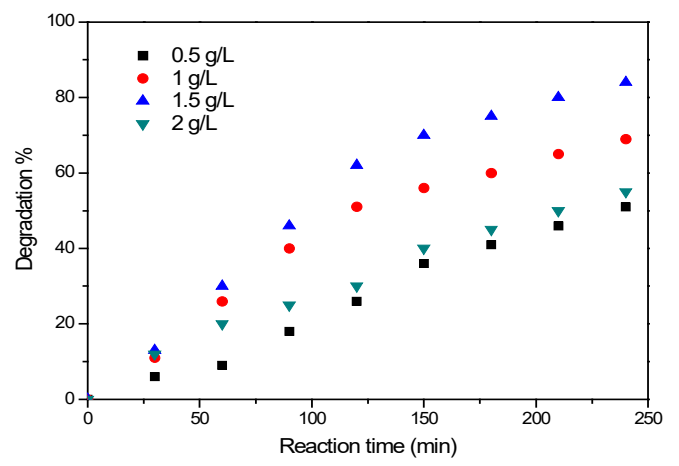

Figure 5. The effect of the photocatalyst dosage on the Rhodamine B degradation under visible light. 


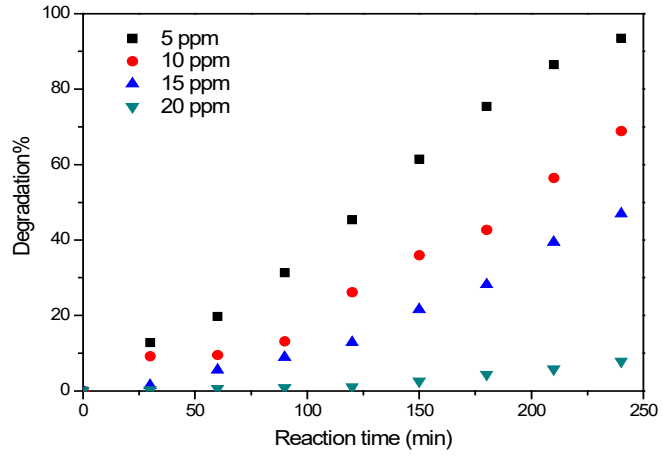

Figure 6. The effect of the initial concentration on the Rhodamine B degradation under visible light.

$\mathrm{pH}<\mathrm{pH}_{\mathrm{pzc}}$, the surface is positively charged $\mathrm{TioH}+\mathrm{H}$ $=\mathrm{TiOH}_{2}{ }^{+}$; if $\mathrm{pH}>\mathrm{pH}_{\mathrm{pzc}}$ surface is negatively charged $\mathrm{TiOH}+\mathrm{OH}^{-}=\mathrm{TiO}^{-}+\mathrm{H}_{2} \mathrm{O}$ [35-37]. The reported point of zero charge for $\mathrm{TiO}_{2}$ is 6.4 [36]. Also ionization state of dye molecule is related to $\mathrm{pH}$; rhodamine $B$ has three positively charged forms: if $\mathrm{pH}<1$ it is $\mathrm{RBH}_{2}{ }^{2+}$, if $\mathrm{pH}=1-3$ it is $\mathrm{RB}^{+}$, if $\mathrm{pH}>4$ it is $\mathrm{Rb}^{ \pm}$[38]. In this study, $\mathrm{pH}$ effect on photodegradation of rhodamine $B$ can not explain with the electrostatic attraction or repulsion forces between the surface and the rhodamine $\mathrm{B}$ ions. Because at $\mathrm{pH} 2.5$, the surface is positively charged $\left(\mathrm{TiOH}_{2}^{+}\right)$and rhodamine $\mathrm{B}$ is in cationic form $\left(\mathrm{RB}^{+}\right)$. The adsorption is expected to be weak in comparison with higher $\mathrm{pH}$ because of repulsion forces of the same charges. However, the maximum degradation was achieved at $\mathrm{pH}$ 2.5, this was attributed to the monomeric form of rhodamine $\mathrm{B}$ molecules at this $\mathrm{pH}$. When $\mathrm{pH}>4$ the zwitterionic form of rhodamine $\mathrm{B}$ molecules are tended to aggregate. The result of aggregation of rhodamine $B$ molecules is the bigger molecular form (dimer) and they are unable to enter the pore of the photocatalyst [39]. That is why the decrease occurred by the $\mathrm{pH}$ increases.

\section{Kinetics}

Langmuir-Hinshelwood rate expression has been fitted well with the relationship between the initial degradation rate and the concentration of the organic dye for heterogeneous photocatalytic processes occurring at the solid-liquid interface $[40,41]$. Langmuir-Hinshelwood kinetic model was given as:

$\mathrm{r}=-\frac{\mathrm{dC}_{\mathrm{e}}}{\mathrm{dt}}=\frac{\mathrm{k} \cdot \mathrm{K} \cdot \mathrm{C}_{\mathrm{e}}}{1+\mathrm{K} \cdot \mathrm{C}_{\mathrm{e}}}$

where $r$ is the initial disappearance rate of the dye, $C_{e}$ is the equilibrium dye concentration, $t$ is the time of the reaction, $\mathrm{K}$ is the equilibrium constant for the adsorption of the organic dye onto the catalyst, and $\mathrm{k}$ is the reaction rate constant. When the dye concentration is very low, $\mathrm{K} \cdot \mathrm{C}_{\mathrm{e}}$ is very small compared to 1 ; the term $\mathrm{K} \cdot \mathrm{C}_{\mathrm{e}}$ is negligible. The equation was integrated with respect to $t$, so it can be expressed as a pseudo-first-order kinetic equation. The term $\mathrm{k} \cdot \mathrm{K}$ was used as $\mathrm{k}_{\mathrm{app}}$ in Equation 5.

$-\ln \frac{\mathrm{C}_{\mathrm{e}}}{\mathrm{C}_{0}}=\mathrm{k}_{\mathrm{app}} \cdot \mathrm{t}$

Apparent first-order rate constants $\left(k_{a p p}\right)$, and corresponding correlation coefficients $\left(R^{2}\right)$ are summarized in Table 2 . The maximum reaction rate constant was found as $9.1 \times 10^{-3} \mathrm{~min}^{-1}$ for 1.0 BaFts $/ \mathrm{TiO}_{2}$ with $1 \mathrm{~g} / \mathrm{L}$ loading and $5 \mathrm{ppm}$ initial dye concentration.

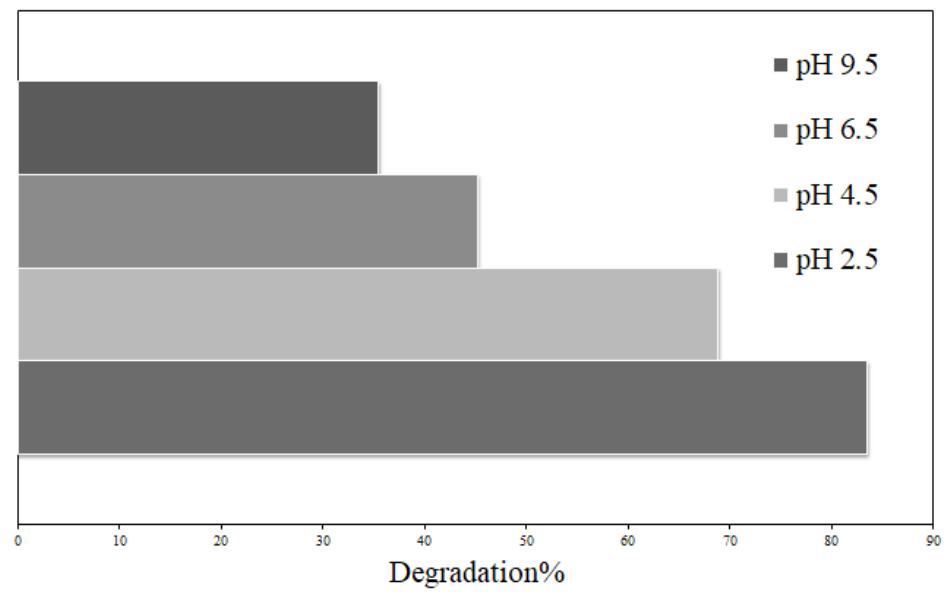

Figure 7. pH Effect on the Rhodamine B degradation under visible light. 
Table 2. Rhodamine B degradation reaction conditions and corresponding result.

\begin{tabular}{|c|c|c|c|c|c|c|}
\hline Photocatalyst & $\begin{array}{l}\text { Initial } \\
\text { dye }\end{array}$ & $\begin{array}{l}\text { Photocatalyst } \\
\text { loading }(\mathrm{g} / \mathrm{L})\end{array}$ & $\mathrm{pH}$ & $\begin{array}{c}\text { Degradation } \\
\%\end{array}$ & $\begin{array}{l}\text { Reaction } \\
\text { Rate } \\
\text { Constant } \\
\left(\mathrm{min}^{-1}\right)\end{array}$ & $\mathrm{R}^{2}$ \\
\hline $\mathrm{TiO}_{2}$ & 10 & 1 & 4.5 & 24.8 & 0.0012 & 0.98 \\
\hline $0.5 \mathrm{BaFts} / \mathrm{TiO}_{2}$ & 10 & 1 & 4.5 & 55.0 & 0.0033 & 0.99 \\
\hline 1.0 BaFts $/ \mathrm{TiO}_{2}$ & 10 & 1 & 4.5 & 68.8 & 0.0051 & 0.99 \\
\hline $2.5 \mathrm{BaFts} / \mathrm{TiO}_{2}$ & 10 & 1 & 4.5 & 59.0 & 0.0042 & 0.95 \\
\hline $5.0 \mathrm{BaFts} / \mathrm{TiO}_{2}$ & 10 & 1 & 4.5 & 44.0 & 0.0024 & 0.99 \\
\hline 1.0 BaFts $/ \mathrm{TiO}_{2}$ & 5 & 1 & 4.5 & 93.5 & 0.0091 & 0.88 \\
\hline 1.0 BaFts $/ \mathrm{TiO}_{2}$ & 15 & 1 & 4.5 & 47.0 & 0.0021 & 0.85 \\
\hline 1.0 $\mathrm{BaFts} / \mathrm{TiO}_{2}$ & 20 & 1 & 4.5 & 7.9 & 0.0003 & 0.83 \\
\hline 1.0 BaFts $/ \mathrm{TiO}_{2}$ & 10 & 0.5 & 4.5 & 51.0 & 0.0029 & 0.98 \\
\hline 1.0 BaFts $/ \mathrm{TiO}_{2}$ & 10 & 1.5 & 4.5 & 84.0 & 0.0077 & 0.99 \\
\hline 1.0 BaFts $/ \mathrm{TiO}_{2}$ & 10 & 2 & 4.5 & 55.0 & 0.0033 & 0.99 \\
\hline 1.0 BaFts $/ \mathrm{TiO}_{2}$ & 10 & 1 & 2.5 & 83.5 & 0.0061 & 0.89 \\
\hline 1.0 $\mathrm{BaFts} / \mathrm{TiO}_{2}$ & 10 & 1 & 6.5 & 45.2 & 0.0026 & 0.97 \\
\hline 1.0 BaFts $/ \mathrm{TiO}_{2}$ & 10 & 1 & 9.5 & 35.5 & 0.0017 & 0.95 \\
\hline
\end{tabular}

\section{CONCLUSION}

This work demonstrates synthesis of barium ferrites loaded $\mathrm{TiO}_{2}$ nanoparticles by a simple twostep method and their usage in photocatalytic processes. The photocatalytic properties were enhanced by the modification and the optimum amount of BaFts was determined. Maximum degradation efficiency was obtained as $93.5 \%$ with 5 ppm initial dye degradation using $1 \mathrm{~g} / \mathrm{L} 1.0$ BaFts $/ \mathrm{TiO}_{2}$.

\section{References}

1. S. Kaur, V. Singh, $\mathrm{TiO}_{2}$ mediated photocatalytic degradation studies of Reactive Red 198 by UV irradiation, J. Hazard. Mater., 141 (2007) 230-236.

2. B. Lee, W. Liaw, J. Lou, Photocatalytic decolorization of methylene blue in aqueous $\mathrm{TiO}_{2}$ suspension, Environ. Eng. Sci., 16 (1999) 165-175.

3. A.N. Ökte, S. Akalın, Iron $\left(\mathrm{Fe}^{3+}\right)$ loaded $\mathrm{TiO}_{2}$ nanocatalysts: characterization and photoreactivity, React. Kinet. Mech. Cat., 100 (2010) 55-70.

4. U.G. Akpan, B.H. Hameed, Parameters affecting the photocatalytic degradation of dyes using $\mathrm{TiO}_{2}$-based photocatalysts: A review, J. Hazard. Mater., 170 (2009) 520-529.

5. H. Park, Y. Park, W. Kim, W. Choi, Surface modification of $\mathrm{TiO}_{2}$ photocatalyst for environmental applications, J. Photoch. Photobio. C, 15 (2013) 1-20.
6. A. Galinska, J. Walendziewski, Photocatalytic water splitting over $\mathrm{Pt}-\mathrm{TiO}_{2}$ in the presence of sacrificial reagents, Energ. Fuel., 19 (2005) 1143-1147.

7. H. Zhang, C. Liang, J. Liu, Z. Tian, G. Wang, W. Cai, Defect-mediated formation of $\mathrm{Ag}$ cluster-doped $\mathrm{TiO}_{2}$ nanoparticles for efficient photodegradation of pentachlorophenol, Langmuir, 28 (2012) 3938-3944.

8. B. Liu, X. Wang, G. Cai, L. Wen, Y. Song, X. Zhao, Low temperature fabrication of $\mathrm{V}$-doped $\mathrm{TiO}_{2}$ nanoparticles, structure and photocatalytic studies, J. Hazard. Mater., 169 (2009) 1112-1118.

9. D.R. Baker, P.V. Kamat, Photosensitization of $\mathrm{TiO}_{2}$ nanostructures with CdS quantum dots: Particulate versus tubular support architectures, Adv. Funct. Mater., 19 (2009) 805-811.

10. Y.C. Nah, A. Ghicov, D. Kim, S. Berger, P. Schmuki, $\mathrm{TiO}_{2}-\mathrm{WO}_{3}$ Composite Nanotubes by Alloy Anodization: Growth and Enhanced Electrochromic Properties, J. Am. Chem. Soc., 130 (2008) 16154-16155.

11. E. Casbeer, V.K. Sharma, X.Z. Li, Synthesis and photocatalytic activity of ferrites under visible light: a review, Sep. Purif. Technol., 87 (2012) 1-14.

12. S.D. Jadhav, P.P. Hankare, R.P. Patil, R. Sasikala, Effect of sintering on photocatalytic degradation of methyl orange using zinc ferrite, Mater. Lett., 65 (2011) 371373.

13. S.W. Cao, Y.J. Zhu, G.F. Cheng, Y.H. Huang, $\mathrm{ZnFe}_{2} \mathrm{O}_{4}$ nanoparticles: Microwave-hydrothermal ionic liquid synthesis and photocatalytic property over phenol, J. Hazard. Mater., 171 (2009) 431-435.

14. M. Su, C. He, V.K. Sharma, M.A. Asi, D. Xia, X. Li, H. Deng, Y. Xiong, Mesoporous zinc ferrite: Synthesis, characterization, and photocatalytic activity with $\mathrm{H}_{2} \mathrm{O}_{2}$ /visible light, J. Hazard. Mater., 211-212 (2012) 95-103. 
15. H. Yang, J. Yan, Z. Lu, X. Cheng, Y. Tang, Photocatalytic activity evaluation of tetragonal $\mathrm{CuFe}_{2} \mathrm{O}_{4}$ nanoparticles for the $\mathrm{H}_{2}$ evolution under visible light irradiation, J. Alloy. Compd., 476 (2009) 715-719.

16. Z.Zhu, X. Li, Q.Zhao, Y.Li, C. Sun, Y. Cao, Photocatalytic performances and activities of Ag-doped $\mathrm{CuFe}_{2} \mathrm{O}_{4}$ nanoparticles, Mater. Res. Bull., 48 (2013) 2927-2932.

17. G. Rekhila, Y. Bessekhouad, M. Trari, Visible light hydrogen production on the novel ferrite $\mathrm{NiFe}_{2} \mathrm{O}_{4}$, Int. J. Hydrogen Energ., 38 (2013) 6335-6343.

18. P. Guo, G. Zhang, J. Yu, H. Li, X.S. Zhao, Controlled synthesis, magnetic and photocatalytic properties of hollow spheres and colloidal nanocrystal clusters of manganese ferrite, Colloid. Surface. A, 395 (2012) 168-174.

19. P. Sathishkumar, R.V. Mangalaraja, S. Anandan, M Ashokkumar, $\mathrm{CoFe}_{2} \mathrm{O}_{4} / \mathrm{TiO}_{2}$ nanocatalysts for the photocatalytic degradation of reactive red 120 in aqueous solutions in the presence and absence of electron acceptors, Chem. Eng. J., 220 (2013) 302 310.

20. P. Sathishkumar, N. Pugazhenthiran, R.V. Mangalaraja, A.M. Asiri, S. Anandan, $\mathrm{ZnO}$ supported $\mathrm{CoFe}_{2} \mathrm{O}_{4}$ nanophotocatalysts for the mineralization of direct blue 71 in aqueous environments, J. Hazard. Mater. 252-253 (2013) 171-179.

21. Y. Hou, X. Li, Q. Zhao, G. Chen, $\mathrm{ZnFe}_{2} \mathrm{O}_{4}$ multi-porous microbricks/graphene hybrid photocatalyst: facile synthesis, improved activity and photocatalytic mechanism, Appl. Catal. B Environ., 142-143 (2013) 80-88.

22. L. Sun, R. Shao, L. Tang, Z. Chen, Synthesis of $\mathrm{ZnFe}_{2} \mathrm{O}_{4} /$ $\mathrm{ZnO}$ nanocomposites immobilized on graphene with enhanced photocatalytic activity under solar light irradiation, J. Alloy. Compd., 564 (2013) 55-62.

23. R. Dom, R. Subasri, K. Radha, P.H. Borse, Synthesis of solar active nanocrystalline ferrite, $\mathrm{MFe}_{2} \mathrm{O}_{4}(\mathrm{M}: \mathrm{Ca}$, $\mathrm{Zn}, \mathrm{Mg}$ ) photocatalyst by microwave irradiation, Solid State Commun., 151 (2011) 470-473.

24. L. Zhang, Y. He, Y. Wu, T. Wu, Photocatalytic degradation of $\mathrm{RhB}$ over $\mathrm{MgFe}_{2} \mathrm{O}_{4} / \mathrm{TiO}_{2}$ composite materials, Mater. Sci. Eng. B Adv., 176 (2011) 1497-1504.

25. Y. Yang, Y. Jiang, Y. Wang, Y. Sun, L. Liu, J. Zhang, Influences of sintering atmosphere on the formation and photocatalytic property of $\mathrm{BaFe}_{2} \mathrm{O}_{4}$, Mater. Chem. Phys., 105 (2007) 154-156.

26. S. Lee, J. Drwiega, D. Mazyck, CY. Wu, W. M. Sigmund, Synthesis and characterization of hard magnetic composite photocatalyst-Barium ferrite/silica/titania, Mater. Chem. Phys., 96 (2006) 483-488.

27. C. Valero-Luna, S.A. Palomares-Sanchéz, F. Ruíz, Catalytic activity of the barium hexaferrite with $\mathrm{H}_{2} \mathrm{O}_{2} /$ visible light irradiation for degradation of methylene blue, Catal. Today, 266 (2016) 110-119.
28. R.A. Candeia, M.A.F. Souza, M.I.B. Bernardi, S.C. Maestrelli, I.M.G. Santos, A.G. Souza, E. Longo, Monoferrite $\mathrm{BaFe}_{2} \mathrm{O}_{4}$ applied as ceramic pigment, Ceram. Int., 33 (2007) 521-525.

29. R. Babuta, I. Lazau, C. Pacurariu, R.I. Lazau, Barium hexaferrite synthesis via the citrate method, Chem. Bull. "POLITEHNICA" Univ. (Timisoara), 59 (2014) 3135.

30. N. Kislov, S.S. Srinivasan, Y. Emirov, E.K. Stefanakos, Optical absorption red and blue shifts in $\mathrm{ZnFe}_{2} \mathrm{O}_{4}$ nanoparticle, Mater. Sci. Eng. B Adv., 153 (2008) 7077.

31. F. Yakuphanoğlu, Electrical characterization and device characterization of $\mathrm{ZnO}$ microring shaped films by sol-gel method, J. Alloy. Compd., 507 (2010) 184-189.

32. M. Asiltürk, F. Sayılkan, E. Arpaç, Effect of $\mathrm{Fe}^{3+}$ ion doping to $\mathrm{TiO}_{2}$ on the photocatalytic degradation of malachite green dye under UV and vis-irradiation, J. Photoch. Photobio. A, 203 (2009) 64-71.

33. W. Septina, S. Ikeda, M.A. Khan, T. Hirai, T. Harada, M. Matsumura, L.M. Peter, Potentiostatic electrodeposition of cuprous oxide thin films for photovoltaic applications, Electrochim. Acta, 56 (2011) 4882-4888.

34. N. Singh, R.M. Mehra, A. Kapoor, Synthesis and characterization of ZnO nanoparticles, J. NanoElectron. Phys., 3 (2011) 132-139.

35. Ö. Kerkez, ì. Boz, Photodegradation of methylene blue with $\mathrm{Ag}_{2} \mathrm{O} / \mathrm{TiO}_{2}$ under visible Light: operational parameters, Chem. Eng. Commun., 202 (2015) 534541.

36. D. Maruthamani,D. Divakar, M. Kumaravel, Enhanced photocatalytic activity of $\mathrm{TiO}_{2}$ by reduced graphene oxide in mineralization of rhodamine B dye, J. Ind. Eng. Chem., 30 (2015) 33-43.

37. R. Vargas, O.Núnez, Hydrogen bond interactions at the $\mathrm{TiO}_{2}$ surface: Their contribution to the $\mathrm{pH}$ dependent photo-catalytic degradation of p-nitrophenol, J. Mol. Catal. A Chem., 300 (2009) 65-71.

38. M.F. Hou, C.X. Mac, W.D. Zhang, X.Y. Tang, Y.N. Fan, H.F. Wan, Removal of rhodamine B using iron-pillared bentonite, J. Hazard. Mater., 186 (2011) 1118-1123.

39. Y. Guo, J. Zhao, H. Zhang, S. Yang, J. Qi, Z. Wang, $\mathrm{H}$. Xu, Use of rice husk-based porous carbon for adsorption of rhodamine $B$ from aqueous solutions, Dyes Pigments, 66 (2005) 123-128.

40. K. Naeem, F. Ouyang, Preparation of $\mathrm{Fe}^{3+}$-doped $\mathrm{TiO}_{2}$ nanoparticles and its photocatalytic activity under UV light, Physica B, 405 (2010) 221-226.

41. Y.H. Xu, D.H. Liang, M.L. Liu, D.Z. Liu, Preparation and characterization of $\mathrm{Cu}_{2} \mathrm{O}-\mathrm{TiO}_{2}$ : Efficient photocatalytic degradation of methylene blue, Mater. Res. Bull., 43 (2008) 3474-3482. 
